\title{
HUBUNGAN PELAYANAN PETUGAS DAN TARIF DENGAN KEPUASAN PASIEN KELAS III DI RUMAH SAKIT UMUM MOKOPIDO KABUPATEN TOLITOLI
}

\author{
Herlina Yusuf \\ Bagian Administrasi dan Kebijakan Kesehatan FKM Unismuh Palu
}

\begin{abstract}
ABSTRAK
Latar Belakang : Pelayanan kesehatan merupakan salah satu aspek yang berperan dalam penciptaan derajat yang merata kepada seluruh masyarakat sesuai dengan tujuan penyelenggaraan pembangunan kesehatan yaitu terwujudnya masyarakat yang mandiri untuk penggapai pelayanan kesehatan dan berperilaku hidup sehat (Depkes RI, 2003). Sumber Daya Manusia yang sehat dan berkualitas memerlukan modala utama atau investasi dalam pembangunan kesehatan. Tujuan penelitian : untuk mengetahui hubungan pelayanan petugas dan tarif dengan kepuasan pasien Kelas III di Rumah Sakit Umum Mokopido Kabupaten Tolitoli. Metode penelitian : survey analitik dengan pendekatan Cross-Sectional yang digunakan untuk mengukur variabel Independent dan Dependent secara bersamaan untuk mengetahui hubungan pelayanan petugas dan tarif dengan kepuasan pasien Kelas III Kabupataen Tolitoli. Sampel : dilakukan dengan cara Accidental Sampling dengan jumlah sampel 91 responden. Hasil penelitian : menunjukkan bahwa ada hubungan yang signifikan pelayanan petugas administrasi antara kepuasan pasien dengan nilai $P=0,000(P<$ $0,5)$ ada hubungan yang signifikan pelayanan perawat antara kepuasan pasien dengan nilai $P=0,000(P<0,5)$ tidak ada hubungan pelayanan dokter antara kepuasan pasien dengan nilai $P=0,087(P<0,05)$ ada hubungan yang signifikan pelayanan petugas apotek antara kepuasan pasien dengan nilai $P=0,000(P<0,5)$ tidak ada hubungan tarif antara kepuasan pasien dengan nilai $P=0,028(P<0,5)$. Saran : kepada instansi khususnya bagi petugas Apotek Rumah Sakit Umum Mokopido Kabupaten Tolitoli dapat lebih meningkatkan kualitas pelayanan di Apotek sehingga dapat meningkatkan kepuasan pasien.
\end{abstract}

Kata Kunci $\quad$ : Administrasi, Perawat, Dokter, Petugas Apotek, Tarif, Daftar pustaka $\quad$ : $22(2000-2014)$

\section{PENDAHULUAN}

Pelayanan kesehatan merupakan salah satu aspek yang berperan dalam penciptaan derajat yang merata kepada seluruh masyarakat sesuai dengan tujuan penyelenggaraan pembangunan kesehatan yaitu terwujudnya masyarakat yang mandiri untuk menggapai pelayanan kesehatan dan berperilaku hidup sehat (Depkes RI, 2003).

Tumbuh suburnya tempat-tempat penyedia layanan kesehatan seperti rumah sakit, klinik, balai pengobatan, merupakan salah satu bukti bahwa produsen telah merespon dan melihat peluang usaha dari kebutuhan masyarakat akan jasa pelayanan kesehatan tersebut. Rumah Sakit Umum Mokopido merupakan salah satu penyedia jasa pelayanan kesehatan yang berada di daerah Tolitoli. Rumah Sakit Umum Mokopido membuka layanan kesehatan selama 24 jam atau dengan kata lain bahwa dokter jaga yang bertugas selalu stand by di rumah sakit kapanpun dibutuhkan oleh pasien yang 
membutuhkan penanganan medis (Profil RSUD Mokopido,2013)

Tujuan pelayanan kesehatan adalah tercapainya derajat kesehatan masyarakat yang memuaskan harapan dan kebutuhan derajat masyarakat (consumer satisfaction), melalui pelayanan yang efektif oleh pemberi pelayanan yang memuaskan harapan dan kebutuhan pemberi pelayanan (provider satisfaction), pada institusi pelayanan yang diselenggarakan secara efisien (institutional satisfaction). Interaksi ketiga pilar utama pelayanan kesehatan yang serasi, selaras dan seimbang, merupakan paduan dari kepuasan tiga pihak, dan ini merupakan pelayanan kesehatan yang memuaskan (satisfactory healty care) ( Djosugitjo, 2001).

2008) $\begin{gathered}\text { Menurut Utama (dalam Asmita, } \\ \text { hakikat }\end{gathered}$ penyelenggaraan pelayanan kesehatan adalah pemenuhan kebutuhan dan tuntutan dari para pemakai jasa pelayanan kesehatan (pasien), dimana pasien mengharapkan suatu penyelesaian dari masalah kesehatannya. Pasien memandang bahwa penyedia jasa pelayanan kesehatan harus mampu memberikan pelayanan medis dalam upaya penyembuhan penyakit dan pemulihan kesehatan yang berkualitas, cepat tanggap atas keluhan pasien, serta penyediaan fasilitas pelayanan kesehatan yang nyaman. Untuk itu, Rumah Sakit Umum Mokopido harus selalu berusaha fokus terhadap Kepuasan pelanggan dan tanggap terhadap setiap pasien yang datang dan dalam memberikan pelayanan kesehatan memakai tenaga yang terampil dan profesional agar pelayanan yang diberikan dapat memenuhi harapan dari pasien.

Sebagai penyedia jasa pelayanan kesehatan, maka seharusnya didalam menjalankan kegiatannya Rumah Sakit mempunyai fungsi yang senantiasa melekat yaitu fungsi sosial dan fungsi bisnis. Dalam menjalankan fungsi sosialnya melayani setiap pasien yang datang untuk mendapatkan pelayanan kesehatan tanpa membeda-bedakan status sosial ekonominya. Setiap pasien yang datang akan dilayani dengan baik walaupun pasien yang datang merupakan orang yang tidak mampu. Untuk menjalankan fungsi bisnisnya sebagai penyedia jasa pelayanan kesehatan swasta, Rumah Sakit Umum Mokopido perlu untuk mempertahankan dan meningkatkan jumlah kunjungan pasien agar mampu memperoleh keuntungan dari kunjungan pasien untuk menjaga keberlangsungan usahanya (Profil RSUD Mokopido,2013)

Dari berbagai definisi dan faktorfaktor yang mempengaruhi kepuasan pasien, maka peneliti menarik kesimpulan bahwa ada empat faktor yang penting dari pelayanan yang diberikan oleh petugas kesehatan dalam mewujudkan kepuasan pasien yang ada di Rumah Sakit Umum Mokopido Tolitoli, yakni Pelayanan Petugas Administrasi, Pelayanan Perawat, Pelayanan Dokter, Pelayanan Petugas Apotek.

Berdasarkan hasil survey diatas maka perlu dilakukan penelitian untuk mengetahui Pengaruh Pelayanan Petugas dan Tarif Terhadap Kepuasan Pasien Kelas III di Rumah Sakit Umum Mokopido Kabupaten Tolitoli. Diantaranya:

Pasien menunggu terlalu lama dibagian pelayanan administrasi pendaftaran karena harus melengkapi persyaratan pelayanan administrasi sehingga pasien merasa bosan menunggu giliran untuk mendapatkan pelayanan.

Petugas kesehatan (dokter) tidak ada ditempat pada saat dibutuhkan, maka pasien merasa tidak dilayani dan pasien yang seharusnya secepatnya mendapatkan pelayanan tetapi masih menunggu lama dan bahkan sampai 
keesokan harinya baru mendapatkan pelayanan.

Ada beberapa perawat dalam menjalankan tugasnya kurang ramah terhadap pasien, sehingga pasien merasa kurang senang saat berkunjung. Di bagian obat, pasien juga kurang puas dikarenakan ada sebagian obat yang diberikan tidak ada tersedia dan cukup sulit di jangkau oleh ekonomi pasien.

\section{BAHAN DAN METODE}

Penelitian ini adalah penelitian analitik dengan menggunakan pendekatan "cross sectional". Di mana variabel independent dan variabel dependent diteliti dalam waktu

\section{Tabel 1}

Hubungan Pelayanan Petugas Administrasi Dengan Kepuasan Pasien Kelas III Di Rumah Sakit Umum Mokopido bersamaan. Penelitian ini dilaksanakan di Rumah Sakit Umum Mokopido Kabupaten Tolitoli. Penelitian ini dilaksanakan pada Juli - Agustus 2014. Populasi dalam penelitian ini adalah keseluruhan pasien Kelas III Rumah Sakit Mokopido Tolitoli. Sampel dalam penelitian ini adalah 91 orang, diperoleh dari hasil perhitungan dengan menggunakan rumus estimasi.

\section{HASIL}

1. Hubungan Pelayanan Petugas Administrasi Terhadap Kepuasan Pasien Kelas III Di Rumah Sakit Umum Mokopido. Kelas III Di Rumah Sakit Umum Mokopido

\begin{tabular}{|c|c|c|c|c|c|c|c|}
\hline \multirow{2}{*}{$\begin{array}{c}\text { Pelayanan } \\
\text { Petugas } \\
\text { Administrasi }\end{array}$} & \multicolumn{4}{|c|}{ Kepuasan Pasien } & \multicolumn{2}{|c|}{ Jumlah } & \multirow{3}{*}{$\begin{array}{c}P \\
\text { Value }\end{array}$} \\
\hline & \multicolumn{2}{|c|}{ Tidak Puas } & \multicolumn{2}{|c|}{ Puas } & \multirow[b]{2}{*}{$\mathbf{n}$} & \multirow[b]{2}{*}{$\%$} & \\
\hline & $\mathbf{n}$ & $\%$ & $\mathbf{n}$ & $\%$ & & & \\
\hline Truan Dain & 9 & 9,9 & 0 & 0 & 9 & 9,9 & \multirow{3}{*}{0,000} \\
\hline Baik & 26 & 28,6 & 56 & 61,5 & 82 & 90,1 & \\
\hline Total & 35 & 38,5 & 56 & 61,5 & 91 & 100 & \\
\hline
\end{tabular}

Sumber: Data Primer Tahun 2014

Berdasarkan tabel 1 menerangkan bahwa dari 91 responden yang menyatakan pelayanan petugas administrasi yang menyatakan tidak baik dan tidak puas sebanyak 9 responden $(9,9 \%)$, sedangkan yang menyatakan puas 0 responden (0\%). Kemudian responden yang menyatakan pelayanan petugas administrasi baik dan merasa tidak puas sebanyak 26 responden $(28,6 \%)$ dan responden yang puas sebanyak 56 responden (61,5\%).
Hasil uji statistik dengan menggunakan rumus chi-Square di peroleh nilai $p$ value $=0,000(p<0,05)$, dengan demikian maka Ho ditolak berarti ada hubungan pelayanan petugas administrasi dengan Kepuasan pasien Kelas III di Rumah Sakit Umum Mokopido Kabupaten Tolitoli.
2. Hubungan Pelayanan Perawat Terhadap Kepuasan Pasien Kelas III Di Rumah Sakit Umum Mokopido. 
Tabel 2

Hubungan Pelayanan Perawat Dengan Kepuasan Pasien

Kelas III Di Rumah Sakit Umum Mokopido

\begin{tabular}{|c|c|c|c|c|c|c|c|}
\hline \multirow{3}{*}{$\begin{array}{c}\text { Pelayanan } \\
\text { Petugas } \\
\text { Perawat }\end{array}$} & \multicolumn{4}{|c|}{ Kepuasan Pasien } & \multirow{2}{*}{\multicolumn{2}{|c|}{ Jumlah }} & \multirow{3}{*}{$\begin{array}{c}\mathbf{P} \\
\text { Value }\end{array}$} \\
\hline & \multicolumn{2}{|c|}{ Tidak Puas } & \multicolumn{2}{|c|}{ Puas } & & & \\
\hline & $\mathrm{n}$ & $\%$ & $\mathbf{n}$ & $\%$ & $\mathbf{n}$ & $\%$ & \\
\hline Tidak Baik & 26 & 28,6 & 12 & 13,2 & 38 & 41,8 & \\
\hline Baik & 9 & 9,9 & 44 & 48,4 & 53 & 58,2 & 0,000 \\
\hline Total & 35 & 38,5 & 56 & 61,5 & 91 & 100 & \\
\hline
\end{tabular}

Sumber: Data Primer Tahun 2014

Berdasarkan tabel 2 menujukkan bahwa dari 91 responden yang menyatakan pelayanan perawat tidak baik dan tidak puas sebanyak 26 responden (28,6\%), sedangkan yang menyatakan puas sebanyak 12 responden (13,2\%). Kemudian responden yang menyatakan pelayanan perawat baik dan merasa tidak puas sebanyak 9 responden (9,9\%), dan responden yang puas sebanyak 44 responden $(48,4 \%)$.
Hasil uji statistik dengan menggunakn rumus chi-Square di peroleh nilai $p$ value $=0,000(p<0,05)$, dengan demikian maka Ho ditolak yang berarti ada hubungan pelayanan perawat terhadap Kepuasan pasien Kelas III di Rumah Sakit Umum Mokopido Kabupaten Tolitoli.

3. Hubungan Pelayanan Dokter Terhadap Kepuasan Pasien Kelas III Di Rumah Sakit Umum Mokopido.

Tabel 3

Hubungan Pelayanan Dokter Dengan Kepuasan Pasien

Kelas III Di Rumah Sakit Umum Mokopido

\begin{tabular}{|c|c|c|c|c|c|c|c|}
\hline \multirow{3}{*}{$\begin{array}{c}\text { Pelayanan } \\
\text { Petugas } \\
\text { Dokter }\end{array}$} & \multicolumn{4}{|c|}{ Kepuasan Pasien } & \multirow{2}{*}{\multicolumn{2}{|c|}{ Jumlah }} & \multirow{3}{*}{$\begin{array}{c}\mathbf{P} \\
\text { Value }\end{array}$} \\
\hline & \multicolumn{2}{|c|}{ Tidak Puas } & \multicolumn{2}{|c|}{ Puas } & & & \\
\hline & $\mathrm{n}$ & $\%$ & $\mathrm{n}$ & $\%$ & $\mathbf{n}$ & $\%$ & \\
\hline Tidak Baik & 21 & 23,1 & 22 & 24,2 & 43 & 47,3 & \\
\hline Baik & 14 & 15,4 & 34 & 37,4 & 48 & 52,7 & 0,087 \\
\hline Total & 35 & 38,5 & 56 & 61,5 & 91 & 100 & \\
\hline
\end{tabular}

Sumber: Data Primer Tahun 2014

Berdasarkan tabel 3 menerangkan puas sebanyak 22 responden (24,2\%). bahwa dari 91 responden yang menyatakan pelayanan dokter tidak baik dan tidak puas sebanyak 21 responden $(23,1 \%)$, sedangkan yang menyatakan Kemudian responden yang menyatakan pelayanan dokter baik dan merasa tidak puas sebanyak 14 responden $(15,4 \%)$, 
dan responden yang puas sebanyak 34 responden $(37,4 \%)$.

Hasil uji statistik dengan menggunakan rumus chi-Square di peroleh nilai $p$ value $=0,087(p<0,05)$, dengan demikian maka Ho diterima yang berarti tidak ada hubungan pelayanan dokter terhadap Kepuasan pasien Kelas III di Rumah Sakit Umum Mokopido Kabupaten Tolitoli.

4. Hubungan Pelayanan Petugas Apotek Terhadap Kepuasan Pasien Kelas III Di Rumah Sakit Umum Mokopido.

Tabel 4

Hubungan Pelayanan Petugas Apotek Dengan Kepuasan Pasien Kelas III Di Rumah Sakit Umum Mokopido

\begin{tabular}{|c|c|c|c|c|c|c|c|}
\hline \multirow{3}{*}{$\begin{array}{c}\text { Pelayanan } \\
\text { Petugas } \\
\text { Apotek }\end{array}$} & \multicolumn{4}{|c|}{ Kepuasan Pasien } & \multirow{2}{*}{\multicolumn{2}{|c|}{ Jumlah }} & \multirow{3}{*}{$\begin{array}{c}P \\
\text { Value }\end{array}$} \\
\hline & \multicolumn{2}{|c|}{ Tidak Puas } & \multicolumn{2}{|c|}{ Puas } & & & \\
\hline & $\mathbf{n}$ & $\%$ & $\mathbf{n}$ & $\%$ & $\mathbf{n}$ & $\%$ & \\
\hline Tidak Baik & 31 & 34,1 & 14 & 15,4 & 45 & 49,5 & \\
\hline Baik & 4 & 4,4 & 42 & 46,2 & 46 & 50,5 & 0,000 \\
\hline Total & 35 & 38,5 & 56 & 61,5 & 91 & 100 & \\
\hline
\end{tabular}

Sumber: Data Primer Tahun 2014

Berdasarkan tabel 4 menujukkan bahwa dari 91 responden yang menyatakan pelayanan perawat tidak baik dan tidak puas sebanyak 31 responden (34,1\%), sedangkan yang menyatakan puas sebanyak 14 responden (15,4\%). Kemudian responden yang menyatakan pelayanan petugas apotek baik dan merasa tidak puas sebanyak 4 responden $(4,4 \%)$, dan responden yang puas sebanyak 42 responden $(46,2 \%)$.
Hasil uji statistik dengan menggunakan rumus chi-Square di peroleh nilai $p$ value $=0,000(p<0,05)$, dengan demikian maka Ho ditolak yang berarti ada hubungan pelayanan apotek terhadap Kepuasan pasien Kelas III di Rumah Sakit Umum Mokopido Kabupaten Tolitoli.

5. Hubungan Tarif Terhadap Kepuasan Pasien Kelas III Di Rumah Sakit Umum Mokopido.

Tabel 5

Hubungan Tarif Terhadap Kepuasan Pasien

Kelas III Di Rumah Sakit Umum Mokopido

\begin{tabular}{|c|c|c|c|c|c|c|c|}
\hline \multirow{3}{*}{ Tarif } & \multicolumn{4}{|c|}{ Kepuasan Pasien } & \multirow{2}{*}{\multicolumn{2}{|c|}{ Jumlah }} & \multirow{3}{*}{$\begin{array}{c}P \\
\text { Value }\end{array}$} \\
\hline & \multicolumn{2}{|c|}{ Tidak Puas } & \multicolumn{2}{|c|}{ Puas } & & & \\
\hline & $\mathrm{n}$ & $\%$ & $\mathrm{n}$ & $\%$ & $\mathbf{n}$ & $\%$ & \\
\hline Mahal & 8 & 8,8 & 27 & 29,7 & 35 & 38,5 & \\
\hline Tidak Mahal & 27 & 29,7 & 29 & 31,9 & 56 & 61,5 & 0,028 \\
\hline Total & 35 & 38,5 & 56 & 61,5 & 91 & 100 & \\
\hline
\end{tabular}

Sumber: Data Primer Tahun 2014 
Berdasarkan tabel 5 menujukkan bahwa dari 91 responden yang menyatakan tarif mahal dan tidak puas sebanyak 8 responden (8,8\%), sedangkan yang menyatakan puas sebanyak 27 responden (29,7\%). Kemudian responden yang menyatakan tarif tidak mahal dan merasa tidak puas sebanyak 27 responden (29,7\%), dan responden yang puas sebanyak 29 responden $(31,9 \%)$.

Hasil uji statistik dengan menggunakan rumus chi-Square di peroleh nilai $p$ value $=0,028(p<0,05)$, dengan demikian maka Ho diterima yang berarti tidak ada hubungan tarif terhadap Kepuasan pasien Kelas III di Rumah Sakit Umum Mokopido Kabupaten Tolitoli.

\section{PEMBAHASAN}

\section{Hubungan Pelayanan Petugas Administrasi Terhadap Kepuasan Pasien Kelas III Di Rumah Sakit Mokopido Kabupaten Tolitoli.}

Berdasarkan hasil analisis bivariat terhadap 91 responden Kelas III di Rumah Sakit Umum Mokopido sebagai responden tentang petugas administrasi, bahwa jumlah pasien terlihat banyak memiliki pilihan baik sekaligus puas yaitu sebanyak 56 responden dan yang memilih pilihan baik sekaligus tidak puas sebanyak 26 responden, sedangkan yang memilih pilihan tidak baik sekaligus puas sebanyak 0 responden dan yang memilih pilihan tidak baik sekaligus tidak puas 9 responden.

Berdasarkan uju chi-square diperoleh nilai $P$ Value $=0,000(p, 0,05)$, dengan demikian maka Ho ditolak yang berarti ada hubungan pelayanan petugas administrasi terhadap kepuasan pasien Kelas III di Rumah Sakit Umum Mokopido Kabupaten Tolitoli.

\section{Hubungan Pelayanan Perawat Terhadap Kepuasan Pasien Kelas III Di Rumah Sakit Umum Mokopido Kabupaten Tolitoli.}

Berdasarkan hasil analisis bivariat terhadap 91 responden Kelas III di Rumah Sakit Umum Mokopido sebagai responden tentang pelayanan perawat, bahwa jumlah pasien terlihat banyak memiliki pilihan baik sekaligus puas yaitu sebanyak 44 responden dan yang memilih pilihan baik sekaligus tidak puas sebanyak 9 responden, sedangkan yang memilih pilihan tidak baik sekaligus puas sebanyak 12 responden dan yang memilih pilihan tidak baik sekaligus tidak puas 26 responden. Berdasarkan uju chisquare diperoleh nilai $P$ Value $=0,000$ $(p, 0,05)$, dengan demikian maka Ho ditolak yang berarti ada hubungan pelayanan perawat terhadap kepuasan pasien Kelas III di Rumah Sakit Umum Mokopido Kabupaten Tolitoli.

\section{Hubungan Pelayanan Dokter Terhadap Kepuasan Pasien Kelas III Di Rumah Sakit Umum Mkopido Kabupaten Tolitoli. \\ Berdasarkan hasil analisis bivariat} terhadap 91 responden Kelas III di Rumah Sakit Umum Mokopido sebagai responden tentang pelayanan dokter, bahwa jumlah pasien terlihat banyak memiliki pilihan baik sekaligus puas yaitu sebanyak 34 responden dan yang memilih pilihan baik sekaligus tidak puas sebanyak 14 responden, sedangkan yang memilih pilihan tidak baik sekaligus puas sebanyak 22 responden danyang memilih pilihan tidak baik sekaligus tidak puas 21 responden.

Berdasarkan uju chi-square diperoleh nilai $P$ Value $=0,087$ ( $p 0,05)$, dengan demikian maka Ho diterima yang berarti tidak ada hubungan pelayanan dokter terhadap kepuasan pasien Kelas III di Rumah Sakit Umum Mokopido Kabupaten Tolitoli.

4. Hubungan Pelayanan Petugas Apotek Terhadap Pasien Kelas 


\section{Di Rumah Sakit Umum Mokopido Kabupaten Tolitoli}

Berdasarkan hasil analisis bifariat terdapat 91 responden di Rumah Sakit Mokopido sebagai responden tentang pelayanan petugas apotek, bahwa jumlah pasien terlihat sedikit memilih pilihan baik sekaligus puas yaitu sebanyak 42 dan memilih pilihan baik sekaligus tidak puas sebanyak 4 Responden, sedangkan yang memilih pilihan tidak baik sekaligus puas sebanyak 14 responden dan yang memilih pilihan tidak baik sekaligus tidak puas sebanyak 31 responden.

Berdasarkan uju chi-square diperoleh nilai $P$ Value $=0,000(p, 0,05)$, dengan demikian maka Ho ditolak yang berarti ada hubungan pelayanan petugas apotek terhadap kepuasan pasien Kelas III di Rumah Sakit Umum Mokopido Kabupaten Tolitoli.

\section{Hubungan Tarif Terhadap \\ Pasien Kelas III Di Rumah Sakit Umum Mokopido Kabupaten Tolitoli}

Berdasarkan hasil analisis bifariat terdapat 91 responden di Rumah Sakit Mokopido sebagai responden tentang tarif, bahwa jumlah pasien terlihat sedikit memilih pilihan tidak mahal sekaligus puas yaitu sebanyak 29 dan memilih pilihan tidak mahal sekaligus tidak puas sebanyak 27 Responden, sedangkan yang memilih pilihan mahal sekaligus puas sebanyak 27 responden dan yang memilih pilihan mahal sekaligus tidak puas sebanyak 8 responden.

Berdasarkan uju chi-square diperoleh nilai $P$ Value $=0,028(p, 0,05)$, dengan demikian maka Ho diterima yang berarti tidak ada hubungan pelayanan petugas apotek terhadap kepuasan pasien Kelas III di Rumah Sakit Umum Mokopido Kabupaten Tolitoli.

\section{KESIMPULAN}

1. Ada hubungan yang signifikan antara pelayanan petugas administrasi dengan kepuasan pasien dilihat berdasarkan nilai $p$ value $=0,000(p<$ 0,05 ).

2. Ada hubungan yang signifikan antara pelayanan perawat dengan kepuasan pasien dilihat berdasarkan nilai $p$ value $=0,000(p<0,05)$.

3. Tidak ada hubungan yang antara pelayanan dokter dengan kepuasan pasien dilihat berdasarkan nilai $p$ value $=0,087(p<0,05)$.

4. Ada hubungan yang signifikan antara pelayanan petugas apotek dengan kepuasan pasien dilihat berdasarkan nilai $p$ value $=0,000(p<0,05)$.

5. Tidak ada hubungan yang antara pelayanan tarif dengan kepuasan pasien dilihat berdasarkan nilai $p$ value $=0,028(p<0,05)$.

\section{SARAN}

1. Diharapkan Kepala Rumah Sakit Umum Mokopido Kabupaten Tolitoli untuk menjalankan pelayanan sesuai Standar Operasional Prosedur (SOP) sesuai kebijakan mengenai pelayanan agar lebih meningkatkan lagi rasa puas yang dirasakan pasien.

2. Diharapkan Instansi Pendidikan agar Penelitian ini menjadi salah satu bahan referensi kepustakaan dalam lima ilmu kesehatan sehingga dapat menambah wawasan pengetahuan khususnya dalam disiplin ilmu Administrasi Kebijakan Kesehatan.

3. Kepada Peneliti yang lain diharapkan adanya pengkajian lebih mendalam mengenai faktor - faktor lain yang dapat mempengaruhi kepuasan pasien.

\section{DAFTAR PUSTAKA}

Aditama, Candra.yoga 2004. Manajemen Adminitrasi Rumah Sakit.Edisi kedua, cetakan ketiga, Penerbit Universitas Indonesia, Jakarta. 
Anjaryani. 2009. Kepuasan Pasien Rawat Inap Terhadap Pelayanan Perawat Di RSUD Tugurejo semarang.

www.undip.ac.id.Dinkes tanggal 18 Mei 2014

Assauri. 2000. PrinsipDasarManajemen. Yogyakarta

Barata A.A (2003). Dasar-dasar Pelayanan Prima. Jakarta: Elex Media Komputindo.

Budiastuti, 2002. Kepuasan Pasien.http://kliniks.wordpress.co $\mathrm{m}$

Diundu 28 Mei 2014

Bambang.2010.Manajemen Pemasaran Untuk Rumah Sakit. Jakarta

Depetemen Kesehatan Repoblik Indonesia 2003.KebijakanDasarPuskesmas DirektoratJendralBinaKesehatanM asyarakat, Jakrta.

Kotler. $2001 . \quad K e p u a s a n P a s i e n$. http://blogspot.com.

Diundu 12 Mei 2014

Lukman, Sampara, Manajemen Kualitas Pelayanan, STIA LAN Pers, Jakarta, 2000 Pelayanan public, Pembaharuan, Yogyakarta 2005.

Siregar. 2003. Definisi dan Struktur Organisasi Rumah Sakit. Rineka Cipta. Jakarta 2004. Farmasi Rumah Sakit Teori Dan Penerapan, Cetakan

I, EGC, Jakarta

Soeroso. 2002. Tingkat Kepuasan Pelanggan. Rhineka Cipta : Jakarta

Sugito, Hadi 2007 Mengukur Kepuasan Pasien. Diambil pada tanggal
$25 \mathrm{Mei}$

2014

http://sugito.wordpress.com

Sulistiono, Eko. 2008. Pelayanan obat rumah sakit. http;//creasoft.wordpress.com, diakses tanggal 26 Mei 2014.

Suprapto,2001,

Kepuasan

Pasien,http://www.Majalah

Kesehatan,Jakarta

Suprianto. 2007. Oprasionalisasi Pelayanan prima, Lembaga Administrasi Negara, RI. Jakarta.

Sutrisno, Edy. 2010. Manajemen Sumber Daya Manusia. Jakarta: Kencana Prenda Media Group.

Sumarwan.2003. Teori Model DiskonektifEksprektif.Airlangga . Jakarta

Tjiptonocandra, 2005.Service, Quality, and Statisfaction: Andi Offset, Yogyakarta

Undang-undang Repoblik Indonesia No.36 tahum 2009 Tentang Kesehatan (lembaran Negara repblik indonesia No. 144 tambahan lembaran repoblik Indonesia

Wigati 2008. Analisis Pengaruh Presepsi Pasien Tentang Mutu Pelayanan Dokter Loyalitas Pasien Di Polikklinik Umum Instansi rawat jalan Rumah Sakit Pantai Wilasa Citarum Semarang Tahun 2008. Program Pasca sarjana Universitas Diponegoro Semarang. www.udip.ac.id. Diakes tanggal 17 Agustus 2014

Wijono. 2000.Manajemen Mutu Pelayanan Kesehatan, Airlangga Universitas Press, Surabaya 